\title{
Perceptions from the Public and Private Sector on Trust and Cooperation in the Field of Environmental Management in Lebanon
}

\author{
Nivine H. Abbas \\ University of Twente / University of Balamand \\ Dr. Irna Van der Molen \\ University of Twente \\ Dr. Manal R. Nader \\ University of Balamand \\ Prof. Jon C. Lovett \\ University of Leeds
}

Doi:10.5901/ajis.2013.v2n8p571

\begin{abstract}
This paper positions trust and cooperation in the context of environmental management in Lebanon. Previous studies indicated increasing environmental problems in this area. The effectiveness of the Lebanese government to address these challenges has been reported to be constrained by large varieties of factors. While 'trust' and 'cooperation' are referred to in literature, it is not systematically studied in the case of Lebanon. This paper assumes that trust and cooperation are reciprocal by nature. It identifies trust and cooperation as a necessary condition for effective environmental management that requires multistakeholder cooperation. Nonetheless, we acknowledge that this trust and cooperation relationship can and has been used by stakeholders to effectively obstruct measures and institutions that could reduce environmental problems. The findings are based on 49 structured and semi-structured interviews with public and private stakeholders plus discussions with citizens. In this study, and from the perspective of public and private sectors, we find that -while cooperation between stakeholders within the public sector, and between public and private sector are considered to be generally weak - trust (or the lack thereof) features less prominent in the explanation for this poor management than expected. On the other hands, respondents state that the extent to which citizens are likely to cooperate in environmental management (in terms of participation in joint activities, compliance with regulations, and adjusting behaviors) is related to trust relations of citizens in the governmental authorities and services they provide.
\end{abstract}

\section{Introduction}

Implementation of public programs is not possible without trust among stakeholders (Tyler 2003; Gilson 2003; Tsang, Burnett, Hills, \& Welford 2009). Scholars refer to a strong link between trust and cooperation (Ferrin et al. 2007; Lundin 2007; Woolthuis 1999; Putnam 1993; Edelenbos \& Erik-Hans 2007). Therefore, it is not surprising, that trust between stakeholders is perceived to be a necessary condition to overcome disagreements in environmental management (Tennberg 2007, p: 322). Trust explains, at least to some extent, why participants in various scenarios choose to cooperate or not (Ostrom and Walker 2003); and cooperation is said to be very important in a resource management process (Ostrom 2007).

Armed conflicts represent a particular threat to the environment. Not only because of direct impacts, but also due to the break-down of trust between different sectors and stakeholders who are involved in managing the country. Lebanon provides a suitable case study area to investigate the role of trust on environmental management in times of conflict because of repeated conflict in the area and lack of literature on the sensitive issue of trust relations (Ker Rault 2009; Allen 2011). Lebanon has been (from 1975) and still is -repeatedly- affected by various armed conflicts such as Lebanese' Civil War, the Isreali war, the Nahr-el Bared Clashes, and the ongoing clashes in Tripoli; all these has caused social fragmentation (Bazzi 2007) leading to weak institutions and increased corruption. Although well recognized locally, but rarely mentioned in academic studies, lack of trust is characteristic of interactions between various actors in 
Lebanese society (Ker Rault 2009:4; Allen 2011). According to Haddad, the violations and corruptions in Lebanon had resulted in a low level of trust in government and politicians (2002).

Environmental protection is considered very weak (IMAC 2009, p: 50$)^{1}$ and country has been, and still is, threatened by environmental degradation associated with armed conflict (Maler 1990 in Takshe el al. 2010); human activities; and political and institutional weakness (IMAC 2007a). Specifically, the repeated disruption of public governance by conflict in Lebanon has prevented appropriate decisions and development of environmental protection laws, thereby exacerbating the damage (Bazzi 2009, Leenders 2012). Similarly, the enforcement of existing of environmental protection regulations and implementation of programs has been lagging behind (IMAC 2009, p: 50; MOE/UNDP/ECODIT 2011, p: 347). There is no one leading agency with overall responsibility for managing the environment and its resources (Abi Saab 2012, p: 4). It is argued that the legislative and organizational structures are many times overlapping with jurisdictions of the various stakeholders who are even not well defined (Abi Saab 2012, p: 4; IMAC 2007a: 8). Also, the national authorities are believed to be highly sectorial (IMAC 2007b, p: 8). There is neither master planning in Lebanon nor there is continuity in program development, implementation or even management; specifically each ministry has its own agenda (LCPS 1996). Although in Lebanon most of the public institutions that are involved directly or indirectly with the environmental protection have developed plans, strategies or programs, yet almost all have operated individually and the complementarily work between them is almost non-existent (Habib 2012,p: 275-6). This is affecting negatively the environmental programs since many of them are a long term programs. As a result, most if not all the Lebanese areas, lack the implementation for environmental management plans or initiatives (IMAC 2009, p: 50). All these threats not only negatively affect the environment, but also public health and economic development (Sarraf et al. 2004, p: 5; World Bank 2007,p: 7). We assume that trust relations have a positive impact on cooperation, and thereby facilitate the implementation of environmental programs and management process.

\subsection{Stakeholders in Environmental Management Processes}

The environmental management process is defined in this research as the development of strategies or activities with the goal "to maintain and improve the state of an environmental resource affected by human activities" (Pahl-Wostl, C 2007, p: 561). Three broad categories of stakeholders are involved in environmental management process in Lebanon, whether directly or indirectly: stakeholders in the public sector, stakeholders in the private sector and citizens.

The environmental management process is primarily in public sector hands. At a national level, the public sector consists mainly of policy makers, ministries, government and its institutes (MOE/UNDP/ECODIT 2011, p: 19). Politicians, normally outside the public sector, are key-decision makers within the ministries and therefore included in our category of the public sector of Lebanon. At the local level it is the municipality, which is charged by law to oversee and implement environmental projects benefiting communities within its area of jurisdiction (IMAC 2007b, p: 70). Nevertheless, many public institutions at both local and national levels are administratively weak and are not able to implement developmental projects or provide adequate services to the citizens (Atallah 2012, p: 1, 3). In addition, and significantly, the private sector, which is considered a secondary stakeholder, also plays an important role in environmental planning and management in Lebanon (IMAC 2007a, p: 63). The private sector is defined broadly, to include private companies, but also academic or research centers, and experts to the extent these are being paid for their services ${ }^{2}$. Private companies work as consultants for the public sector, as contractors, or as providers of specific services, such as collecting solid waste or water supply. The public and private sector are closely related and, to some extent, interwoven. Various forms of 'cooperation' between the public and privates sector in the environmental management are: (a) cooperation in project implementation, (b) cooperation through advisory work or consultation; (c) cooperation through contracting or (d) through service provision.

A number of 'councils and funds' play a key role in the disbursement of funds from public to private sector; and a number of joint-stock ventures were established. These funds, councils and joint-stock ventures have played a crucial

\footnotetext{
${ }^{1}$ The Integrated Management of East Mediterranean Coastline (IMAC) overall objective is to stimulate sustainable development of coastal zones in Lebanon with positive effects for standard of living and ecosystem health. The importance of this project is that there is rarely if not no other similar projects implemented about this topic in this area specifically and Lebanon generally, http://www.balamand.edu.lb/english/IMAC.

${ }^{2}$ In Lebanon, the academic and research centers and experts have a role also in the environmental management process. In fact, these centers play a role mainly as a consultation and implementing studies. Also experts, who work in private companies or Ngo's or individually participate in environmental studies and work as consultant to both public or other private stakeholder.
} 
role in rehabilitation and reconstruction of major infrastructure, and thereby have an impact on the environment. Last but not least, citizens can play a crucial role in the environmental management process through complying with laws and regulations, by volunteering in environmental initiatives, or by resisting new plans. The role of Environmental NGOs is still very limited in the North of Lebanon, and therefore not included as specific category.

\section{Objective}

The main objective of this article is to identify the perceptions of trust and cooperation relations (a) among the stakeholders in the public sector and (b) between the stakeholders in the public and private sector ${ }^{3}$. Respondents are stakeholders in the public and private sector. Additionally, we identify their perception of citizens' cooperation mainly the citizens' compliance with laws, regulations and their participation (volunteering) in environmental initiatives. We explicitly relate this to trust. The research also aims to understand the main reasons behind these findings. There are two assumptions in this article. The first is that lack of trust among the stakeholders in public sectors or between the stakeholders in public and private sectors who are involved in the environmental management process is leading to low level of cooperation and constrains progress of planned projects, and sometimes removal or stopping of some projects (IMAC 2007a,p: 13). Second, is that lack of trust of citizens in the stakeholders of public or private sector is leading them to lack of compliance with environmental laws and regulations and to lack of participation in environmental activities. This also leads to many problems in implementing environmental management plans and programs. The outcomes will allow us to understand trust and cooperation relations in Lebanon, in the main sectors involved in the environmental management process, from the stakeholders of public and private sector viewpoint. This research identifies trust and cooperation as a necessary condition for effective environmental management that requires multi-stakeholder cooperation; keeping in mind the fact that some stakeholders in Lebanon successfully circumvent environmental regulations. These stakeholders use the "wasta" or links that is basically relying on their trust and cooperation with public authorities to effectively obstruct measures that could reduce environmental problems.

A total of 49 interviews containing both structured and open questions were implemented with the stakeholders of public and private sector involved in the environmental management process in Lebanon starting from September 2011 till December 2012. The paper is organized as follows. The next section 2 outlines general theories of trust and it relation to cooperation. The methodology is contained in Section 3. Section 4 presents and discusses the results to elucidate, from the public and private stakeholders' perception, the trust and cooperation relations. The final section of this paper draws conclusions and recommendations.

\section{Theoretical background}

\subsection{Definition of trust}

In literature, there are many definitions for trust. A systematic review of academic literature on trust by Fulmer and Gelfand (2012, p: 1171) shows three dominant conceptualizations. Those that refer to 'positive expectations of trustworthiness', those that refer to a 'willingness to accept vulnerability', and those that refer to both. According to Fulmer and Gelfand, the positive expectations of trustworthiness are related to "perceptions, beliefs or expectations about the trustee's intention and being able to rely on the trustee" while "willingness to accept vulnerability [which] generally refers to suspension of uncertainty (Möllering 2006) or an intention or a decision to take risk and to depend on the trustee" (Fulmer and Gelfand 2012, p. 1171). This study adopted as a conceptual definition of trust that of Morton Deutsch that could be applied for various actors mainly the citizens, public and private sectors: "To trust another person lorganization to produce a beneficial event $X$ [add:] or to provide a service, an individual/organization must have confidence that the other individual/organization has ability and intention to produce it" (adjusted from Deutsch 1960, p: 125). Although this definition may seem to be outdated, we found it is still valid and applicable on the various stakeholders involved in the environmental management in Lebanon. This definition was communicated with the people who were interviewed. This definition focuses on specific expectations of trustworthiness, as it refers to ability, to benefits (the event or service provided), and to the intention of the trustee (benevolence to do well). It refers to expectations of trustworthiness (the first dominant conceptualization), but not to the willingness to accept vulnerability (the second

\footnotetext{
${ }^{3}$ Stakeholders involved in environmental management
} 
dominant conceptualization).

This definition can be positioned within Social Exchange Theory (Axelrod 1984; Deutsch 1958): citizens are willing to comply with rules and regulations, to adjust their behavior, if and when they have confidence in private or public sector organizations to be able to produce a beneficial event or to provide beneficial services. According to this research one of the means to have confidence is to build trust relations. Similarly, actors in the private sector are willing to invest in cooperation with organizations in the public sector or with actors in the political domain, when they expect this relation will be beneficial on the short, medium or long term. ${ }^{4}$

\subsection{Trust and cooperation}

Trust and cooperation are reciprocated by nature. Scholars have stated that trust, at various levels, enhances cooperation (Ferrin et al. 2007; Lundin 2007; Woolthuis 1999; Edelenbos \& Erik-Hans 2007, etc.). One of the reasons for that is that parties recognize and feel bound by certain values such as fairness, cooperation, and reciprocity; this will encourage these parties to have more cooperation among each other (Koeszegi 2004; Parkhe 1993). In other word, a party who has earned another's trust will feel bound to that trust and will work to honor it and as a result will behave cooperatively rather than competitively toward the other (Ferrin et al. 2007,p:477). On the other hands, as observed by Ferrin et al, one of the means to develop mutual trust perceptions can be based on cooperative behaviors. These behaviors are said to play a significant intervening role by transmitting one party's trust perceptions to another (Ferrin et al 2008, p: 171). In other words, according to Ferrin et al, there is clear evidence that cooperation "is a critical intervening variable in the development of mutual trust perceptions between individuals and groups" (2008, p: 171). This research shows that in order to improve the environmental management in Lebanon, it is vital to improve the trust relations between the stakeholders involved; thus leading to more cooperation and reciprocity. This in return will develop the mutual trust perceptions among these multi-stakeholders.

\section{3 "Wasta" concept and its relation to trust}

In Lebanon as in many other Middle Eastern societies, 'cooperation' has two faces: one that improves chances of successful implementation of policies and programs; and one that seems to achieve the opposite. The cooperation between some stakeholders takes also place through a practice that is referred to as 'wasta': an "implicit social contract, which obliges those within the group to provide assistance (favorable treatment) to others within the group" (Barnett et al 2013 , p: 2). Smith et al. describe it as "the process whereby one can achieve goals through links with key persons in positions of high status (Smith et al. 2012, with reference to Cunningham \& Sarayrah 1993). Barnett et al. argue that, in the Middle East, "It [wasta] is deeply embedded in the fabric of these societies and visible in everything from the way in which governments interact with businesses to the way in which public policy is formulated" (Barnett et al. 2013, p: 41). Similar to trust, wasta lowers the transaction costs and improves chances of successful cooperation - also when this is counterproductive for environmental protection ${ }^{5}$. According to Cunningham \& Sarayrah (1993) the wasta is not limited to a particular sector of human interactive. In other words, this paper distinguishes between the trust and cooperation relationship that is positively affecting the environmental management, and by the fact that some stakeholders use the "wasta" which is based on trust and cooperation relations with public authorities, to successfully circumvent environmental regulations. Thus, this can reflect the negative manifestation of trust and cooperation relationship on the environmental management in Lebanon.

\subsection{Trust and endurance of organizations:}

As stated by Barnard, it is mentioned that cooperation is considered crucial for the endurance of organizations (1938). Also, it is stated by scholars such as Kounzes and Posner, that trust which is at the heart of collaboration is a crucial and central issue in relationships within and outside organizations (2002,p: 244). Organizational trust in organizations can

\footnotetext{
${ }^{4}$ Other theories that explain trust across organizational levels are: social information processing theory; attribution theory; embeddedness theory; social identity theory, cultural theory and performance based theory. We refer to Fulmer and Gelfand (2012) for a discussion of these theories.

${ }^{5}$ Many of such examples are described in Leenders, 2012, in particular on the quarry industry, waste management and reconstruction.
} 
reduce transaction costs, increase the willingness to cooperate and ensure continuous cooperation. It enhances partnership performance, and encourages innovation. At the same time, however, it can also result in ethnically questionable transactions (Fulmer and Gelfand 2012, p: 1181-1183). This research shows that trust and cooperation are both important and crucial for the relationship within and outside the public and /or public organizations that are involved in the environmental management process in Lebanon. It identifies trust and cooperation as a necessary condition for effective environmental management that requires multi-stakeholder cooperation.

In short, many scholars have discussed the relationship between trust and cooperation. This research will use these theories to explain the results found and will stress on the importance of this relation among the various stakeholders involved in the environmental management process in Lebanon. The next section will explain the methodology and method used in this research.

\section{Methodology}

Most of the data used in this article is gathered from a primary source. Only few are from secondary data and literature. The primary data gathered is from 49 interviews conducted with public and private sector stakeholders who are involved in the environmental management process in Lebanon.

\subsection{The Interviews:}

To begin with, most of the interviews made were personal, only few were made by email. To schedule the interviews, all the interviewees were contacted either by phone or by email. A letter was sent to all of them either by fax or email to explain the purpose of these interviews and a draft of the interview questions was attached. Then a follow up contact was made with each interviewee to schedule the time, date and place of the interview based on the interviewee's preference.

The interviews were both structured and semi- structured interviews. To begin with, in the structured interviews, first all the interviewees were asked the same questions and in the same order. The answers were in the form of rating scales mainly 5 likert scale measurement for example: ranging from 1 (strongly agree) to 5 (strongly disagree). Sometimes in the analysis phase, these 5 scale measurements were summed up into 2 scale only example: 0 (disagree) and 1 (agree). These predetermined answer- rating scales increase the reliability across interviews and the objectivity of judging the interviewees responses (Campion et. al 1988, p: 28). Also to justify the content validity of assessment procedures, it is crucial to make the scoring system explicit (Sackett 1987). In other words, the structured form interview insures that all the interviews are assessed accurately. Also, to enhance consistency, the same interviewer was used in all these interviews. All the questions asked in these interviews were to study to what extent the interviewees believe there is trust and cooperation between the various stakeholders involved in the environmental management process.

The semi -structured interview was selected as the mean to collect the remaining data for the following reasons. First of all, this method is said to be well suited for exploration of the perceptions and believes of the interviewers regarding sensitive and complex issues (Barriball \& While 1994) such as trust. Also it allows searching for more information and clarification of answers by asking open ended questions such as why there is or isn't trust between the public and private sector involved in the environmental management process in Lebanon? Etc. Also by asking same questions that is with the same wordings and sequence to all the interviewees we can be sure that the differences in the answers are due to difference opinions among the interviewees and not due to the differences in the questions asked ( Barriball \& While 1994,p:330). This research also made sure that all interviewees have shared a common vocabulary and meanings for the key words. This is very important for the researcher not to misunderstand the interviewees answers and thus to analysis better in an objective way especially if we want to compare the perception of different interviewees (Denzin 1989), as this article is doing, on a complex issue like trust which can have many meanings.

Before the interviews were conducted, a pilot test was implemented. Accordingly, some of the questions of these interviews were amended and adjusted for accuracy and simplicity as to have its final form. From the 49 interviewees that were contacted ${ }^{6}$, only few interviews were not implemented due to refusal or lack of interest of the interviewees. In general, the data was collected by sectors starting from September 2011 till December 2012. In the public sector, the main stakeholders that were interviewed were representatives of the municipalities, ministries, and public institutes that are involved in the environmental management process. There were 24 interviews conducted with presidents or 
representatives of presidents of the municipalities from the target area. Also interviewed were conducted with representatives of seven ministries that are mostly involved in the environmental management in Lebanon: ministry of Environment, ministry of Interior and Municipality, ministry of Energy and Water, ministry of Agriculture, ministry of Health and ministry of Public works and Transportation. As for the public institutes, only few were interested in having an interview; those were the Council for development and reconstruction, High Relief Council, \& Tripoli Environment \& Development Observatory.

On the other hand, in the private sector, the main stakeholders that were interviewed were representatives of the private companies, academic and research centers, and experts in environment. As for the private companies these mainly included the consultant companies and the ones that provide services. Five interviews were conducted with the following: Lavajet, ECODIT, MORES, ELARD and CRI. In addition, this research tried to interview some industrial factories (five companies) since it is believed that the industrial sector is one of the important sectors that are having a negative impact on the environmental of the area (IMAC 2007a, p: 35-36). Nevertheless, only one accepted to have an interview. As for the research and academic centers, interviews were conducted with only three centers that accepted to do interviews: Water Energy \& Environment Research Center at NDU, The Energy Research Group at AUB and CREEN at USJ. Also experts in different environmental issues were interviewed. Twelve have been contacted but only six accepted or were interested to do interviews. It was generally noticed that some private sector were not willing or able to participate in the interviews; according to some the data they have is confidential.

\section{Results and Discussion}

\subsection{Trust and cooperation relations among stakeholders of public sector:}

The interviewees were asked to give their opinion about the following statement: "From your experience, how can you evaluate the cooperation among the public stakeholders involved in the environmental management process (local and national)?" the following results were found. To begin with, in the public sector, 22 out of 34 public stakeholders stated that the cooperation among the public stakeholders involved in the environmental management process is a weak one (15 out of 24 municipalities, 5 out of 7 ministries and 2 out of 3 public institutes). Similarly, all of the private stakeholders' interviewees perceive that this cooperation is also weak (6 private companies, 3 academic and research centers and 6 experts). One the other hands, literature has mentioned the important role of cooperation in developing mutual trust between groups (Ferrin et al 2008, p: 171), in endurance the public institutes and organizations (Kounzes and Posner 2002, p: 224), and in improving resource management process (Ostom 2007). According to the perception of stakeholders of public and private sector this research reveals that there is a weak cooperation among the stakeholders of public sector and this is affecting negatively the trust relations, the endurance of the public institutes and the environmental management process of this area.

\subsubsection{What are the reasons behind this weak cooperation?}

When the interviewers were asked an open question why they believe there is a weak cooperation within public stakeholders? The following reasons were stated. To begin with the public sector, the main reasons that were mentioned by the ministries were the lack of trust among the different parties involved, lack of continuous cooperation only limited to specific projects, lack of good citizenship, the absence of monitoring, weakness of government, and lack of budget and human resources. Also as for the public institutes, only one has answered this question by stating that the lack of planning for the future and the personal interest are the main reasons behind the weak cooperation among the public stakeholders .On the other hand, from the private sector perception, according to the private companies the main reasons that were stated were the war and conflicts, lack of communication, exchange of knowledge and enforcement of applicable regulations, the conflict of interest in terms of responsibilities, effect of private interests of certain decision makers, and the conflicting mandates and the political tensions. As for the academic and research centers, the main reasons that were stated were the conflict, competition on powers and the lack of implementations of laws by some stakeholders. Also different experts have stated different reasons. Some has stressed on the long history of weak cooperation to be one of the factors that are leading to this weak cooperation. This point is also confirmed by many scholars (Ferrin et al 2007p:480; Pilisuk \& Skolnick 1968). Also other reasons were mentioned by other experts mainly the consideration of certain ministries to be of higher power than other stakeholders, the desire of every stakeholder to be the first in charge of any plan, project, strategy and decision , the lack of team work spirit, the overlapping in authorities or 
terms of references between stakeholders, the personal interest, the corruption and the different political affiliation, and the lack of commitment and responsibility within the employees in the public institutes .

Therefore, both the public and private stakeholders have mentioned many reasons behind this weak cooperation, one of which is trust. To focus on this point, the interviewees were asked to state their opinion about the following statement: "Do you agree that this cooperation among the public stakeholders involved in the environmental management process in Lebanon is related to trust relations?" the following results were found. First of all, according to the stakeholders of the public sector 22 out of 34 of the public stakeholders stated that they agree that the cooperation is related to trust relation (15 out of 24 municipalities, 5 out of 7 ministries and 2 out of 3 public institutes). This answer can be confirmed also by many scholars (Ferrin et al. 2007; Ferrin et al. 2008, p: 168; Koeszegi 2004). Thus, one of the factors that able us to have more cooperation is by working on building more trust.

On the other hand, the data analysis showed that the private sector perception regarding this issue was somehow different. In fact results showed that 2 out 6 private companies "agreed" and 3 out of 6 "disagreed" and one answered "don't know". Also, 2 out of 3 academic and research centers and 4 out of 6 experts answered that they disagree on this statement. In other words, data analysis showed that 9 out of the 15 private stakeholders disagree that the cooperation among the public sector stakeholders is related to trust. In fact many of the private interviewees as shown before, from the information gathered in the interviews, related weak cooperation to other factors such as war, private interests of the decision makers, political tensions, lack of implementations of laws, overlapping in authorities, corruption, etc. Although trust feature less prominent than expected in the explanation of the weak cooperation and thus poor management, yet this research shows that some of these other factors mentioned can be directly or indirectly related to trust. For example, in literature scholars state that there is a strong link between war or arm conflicts and trust (Takshe el al. 2010).

\subsection{Trust and cooperation relations between stakeholders of public and private sector:}

The interviewees were asked to give their opinion on the following statement: "From your experience, how do you evaluate the cooperation between the stakeholders of public and the private sectors involved in the environmental management process?", and the following results were found. First from the stakeholders of public sector's perspective, 23 out of 34 public stakeholders stated that the cooperation between the public and private stakeholders involved in the environmental management process is a weak one (18 out of 24 municipalities, 2 out of 3 of the other public institutions, and 3 out of 7 ministries). On the other hand, according to the private sector interviewees, results showed that 10 out of 15 private stakeholders perceived that there is a weak cooperation between the public and private stakeholders involved in the environmental management process in Lebanon ( 3 out of 6 private companies, 3 out of 3 academic and research centers and 4 out of 6 experts). Thus, the perception that there is a weak cooperation between the public and private stakeholders involved in the environmental management process in Lebanon was confirmed from both the public sector and private sector interviewers. This research reveal that this weak cooperation between the stakeholders of the main sectors involved in the environmental management process is affecting badly the environmental management process; this idea is confirmed in literature (Ostrom 2007). Why is that? This research shows that this weak cooperation is affecting negatively the trust relation between stakeholders of these two sectors since it is claimed that one of the means to develop mutual trust perceptions can be based on cooperative behaviors (Ferrin et al. 2008). This is reflected badly on the environmental management's programs and plans in Lebanon.

\subsubsection{What are the reasons behind this weak cooperation?}

When the interviewers were asked as an open question to state why they believe there is weak cooperation between stakeholder of public and private sector, the following reasons were stated. To begin with the public sector, the main reasons that were stated by the ministries were mainly the weak administration and moody in dealing in the public sector, the fact that the private sector is stronger nowadays than the public sector, the lack of compliance of laws by some sectors, the limitation of cooperation to specific projects, the lack of trust of the private sector in the public sector, and the lack of budget and human resources in the public entities. As for the public institute, only one of the interviewees has an answer to this question; and the main reason for this weak cooperation according to it was the lack of agreement among the various stakeholders. On the other hand, from the private interviewees' perception, according to the private companies, the main reasons were the deficiency and weakness in the municipality organization; the lack of cooperate with the request and demands of this private company, and the lack of trust of the private sector in the public sector. As for the academic and research centers, the main reasons mentioned were the fact that there is no real environmental 
management process in Lebanon, the lack of trust of the private sector in the public sector, the lack of expertise in human resources or financial resources in public sector, the lack of willing of the public sector to cooperate with the private sector. Furthermore, the experts perceived the main reasons to be lack of trust relations, the bureaucratic system and the lack of motivation among the public sector, the slow pattern for work movement in the public versus the fast pattern along the private sector, the availability of profession and know -how in private sector which is not corresponding available in many cases in the public sector. Nevertheless, still some experts believe that there is a strong cooperation between the public and private sector mainly because of common interest. It is stated that public funds and consult private sector for better skills, and private sector cooperate and work with the public sector for money and to open network.

In other words, the answer of the public and private stakeholders to the open question explained many reasons behind this weak cooperation, one of which is the lack of trust. To focus on this point more, the interviewers were asked to give their opinion on the following statement : "Do you agree that this cooperation between the public and the private sectors involved in the environmental management process in Lebanon related to trust relations?", and the following results were found. To begin with the public sector interviewees, 16 out of 24 municipalities and 5 out of 7 ministries agreed on this statement; while 2 out of 3 public institutes answered that they "don't know". In total, 21 out of 34 of the public stakeholders stated that they agree that the cooperation between the public and private stakeholders is related to trust relation. On the other hand, from the private sector stakeholders' perception, the results showed that 9 out of the 15 private stakeholders also agreed on this statement (3 out 6 private companies, 2 out of 3 academic and research centers and 4 out of 6 experts).In other words, both the public and private sector interviewees agree that the cooperation between the public and private stakeholders involved in the environmental management in Lebanon is related to trust relations. This result can be confirmed by many scholars (Ferrin et al. 2007; Lundin 2007; Edelenbos \& Erik- Hans 2007; koeszegi 2004; Parkhe 1993). Thus, based on the public and privates interviewees' perspective, this research claims that building trust relation between the public and private stakeholders is essential for having more cooperation among these multistakeholders and thus having a more successful decisions, developmental plans or environmental projects. This research agrees with Kounzer and Posner that trust is crucial for relationships within and outside organizations (2002). Also this article reveals that trust and cooperation are both central for the relationship within and outside the public and /or public organizations that are involved in the environmental management process in Lebanon.

There are two other statements asked in the interviews that were used to confirm this idea. The first is "from your experience do you agree that the more we have trust, among the public and/or private sectors involved in the environmental management process, the more we will have cooperation between them?" And the second is "if you have trust and cooperation among the stakeholders involved in decision making, then more and better decisions will be taken regarding environmental management process in Lebanon". In both statements 34 out of 34 public and 14 out of 15 private interviewees answered that they agree.

\subsection{To what extent the citizen cooperation with the environmental management initiative is related to trust?}

When the interviewees were asked to give their opinion about statement: "Do you agree that the level of cooperation of the citizens involved with an environmental management initiative is related to the extent of trust between the citizens and the implementing agency (entity)?" the following result was found. To begin with the public sector perception, 17 out of 24 of the municipalities, 7 out of 7 of the ministries and 2 out of 3 of the public institutions agreed on this statement. On the other hands, in the private sector 5 out of 6 private companies, 2 out of 3 academic and research centers and 4 out of 6 experts also agreed on this statement. Thus, the majority of both the public stakeholders (26 out of 34 ) and the private stakeholders interviewed (11 out of 15) agree that the level of cooperation of the citizens involved with an environmental management initiative is related to the extent of trust between the citizen and the entity that is implementing this initiative. This result can be explained again by many scholars who claim that there is a link between trust and cooperation (Ferrin et al. 2007; Woolthuis 1999; Edelenbos \& Erik- Hans 2007). In other words, this research shows that in Lebanon, it is essential to develop more trust relations between the citizens and the public or private sectors involved in the environmental management process, in order to have more citizen participation in the environmental management activities.

Moreover, when the interviewees were asked to reply to statement : "From your experience, do you agree that the decisions that are given by a person that people trust are implemented more often than when given by a person that people doesn't trust?", a common answer was found between the public and private stakeholders. In fact, all the 49 interviewees agreed on this statement. In other words, based on the public and private interviewees' perspective, this research agrees with the Social Exchange theory and deduced that in order to make the citizen cooperate and comply 
the environmental laws or decisions, we need to work on building more confident and trust relations between them and the decision makers. This research stress the importance of citizen cooperation for improving the environmental management process in Lebanon mainly in terms of participation in joint activities, compliance with regulations, and adjusting behaviors.

\subsection{Trust and cooperation's negative effect on environment management:}

This research also acknowledge that this trust and cooperation relationship with certain public authorities can and has been used particular by some stakeholders to effectively obstruct measures and institutions that could reduce environmental problems. When doing interviews with the ministries' representatives, some of the interviewees stated that it is known that some citizens or private sectors usual use their "wasta" to make policemen turn their eyes on their disobedience or lack of compliances for a certain laws. This is a good example that illustrates how trust and cooperation can be used because of a common interest to obstruct measures that could reduce environmental problems. This point was also confirmed by other scholars who also talked about the wasta concept and how it is embedded deeply in the fabric of many Middle Eastern societies one of which is Lebanon (Barnett et al. 2013, p: 41). In fact, literature also mentions other examples of the negative manifestations for trust and cooperation relation on the environmental management in Lebanon. The solid waste management can be a good case to illustrate this issue. Although some reports claim that Beirut city can collect its own waste about half the coast charged by the private companies, yet these reports were chosen to be ignored (Antoun et al. 1998, p: 79; Wakim 1998, p: 157). Leenders has mentioned that some private companies that deal with solid waste management in Lebanon use their trust and cooperation relationships with some Lebanese political leaders or public institutes to get a certain agreement with the government or to renew its initial agreement (2012 p:55,56). In fact, according to Michael al Murr, a previous interior minister, $70 \%$ of a certain company went as a commission to top leaders in the government (Daily Star 21 July 2003 in Leenders 2012,p: 56). Sometimes these private companies give the leaders a controlling stake in the companies too (Leenders 2012, p: 57). In other words, the private companies that deal with solid waste management trust the leaders, because of personal interest and financial benefit, to cooperate with them and assist them in taking certain agreements and contracts with the government. This was confirmed by a manger of a private company who stated that politics goes very well with garbage business you have to build trust and close relations with politicians in order to enter that area and they want a service from you in return (Daily Star 13 April 1999 in Leenders 2012, p: 57).

\section{Conclusion}

To sum up, this article shows that in Lebanon, the stakeholders of public and private sector perceive that there is weak cooperation among the stakeholders of public sector and between the stakeholders of public and private sector involved in the environmental management process. Also many reasons were found to affect this weak cooperation. This research found that lack of trust is perceived mainly by the private sector to be less prominent than expected in the explanation for the weak cooperation especially that is found among the public sector. In fact, many of the private sector interviewees linked the weak coordination to other different reasons such as corruption, overlapping authorities, lack of implementation of laws, war, etc. Nevertheless, this research argues that some of these factor can be linked directly or indirectly to trust. Also this research showed that both public and private sector interviewees agree that the level of cooperation of the citizens involved in the environmental management initiatives is related to the extent these citizens trust the implementing agency or entity. In other words, this research identifies trust and cooperation as a necessary condition for effective environmental management that requires multi-stakeholders. Nonetheless, this research acknowledges and shows that this trust and cooperation relationship has been used by some stakeholders to effectively obstruct measures that could reduce environmental problems. This issue was also support in literature.

Because of the repeated conflict in the area, Lebanon is considered to be an interesting case study to investigate the role of trust on the environmental management in times of conflict. Rarely academic studies have mentioned the lack of trust although it is believed to be characteristic of interactions between various actors in Lebanese society (Ker Rault 2009:4; Allen 2011). Nevertheless, in Lebanon information about lack of enough environmental protection and weak environmental management process do exist (IMAC 2007a; Abi Sab 2012; Sarraf et al. 2004). This researched has reveals that trust and cooperation relationship between the various stakeholders involved in the environmental management process in Lebanon is one of the factors that are affecting this environmental management process.

This article agrees with Mwangi who argues that the possibility to tackle environmental problems requires trust and 
cooperation between different actors (2000, p: 78 ). Both the assumptions raised in this article were proven to be right. In other words, based on the perception of public and private interviewees, this article shows that lack of trust, whether it is within the stakeholders of public sector, between the stakeholders of public and private sectors or by the citizen toward the stakeholders of public or private sector, is affecting negatively the environmental management process in Lebanon. Thus, in order to improve the environmental management, it is vital to work on enhancing the trust and cooperation relations among the various stakeholders involved in this process. Nevertheless, this article recommends these various stakeholders to keeps in mind what some scholar argues that trust is slow to grow and easy to break (Beratan 2007;Gray et al 2012). This research doesn't claim that trust and cooperation relationships are the only reason behind lack of environmental management process in Lebanon; nor does it argue that trust is the only reason that boosts cooperation. However, this article reveals that according to the public and private interviewees, trust indeed can have a vital effect and play a significant role in the environmental management process in Lebanon. This article is part of a larger research which is generally studying the trust relations and its effect on the environmental management process in Lebanon from different perceptions. It recognizes itself as a pilot test suggesting and encouraging future researches in the same field to conduct similar researches or comparative perspective on multiple areas studies not only in different area in Lebanon but also in other countries .

\section{References}

Abi Saab, M A. (2012). Marine Biodiversity coastal waters. In Review and perspectives of environmental studies in Lebanon (pp. 1-30). Edited by Kouyumjian \& Hamze, National Council for Scientific Research. Lebanon.

Allen, M. (2011).Trust: the absent keystone in Lebanese democracy. Middle East Political And Economic Institute. Retrieved from http://mepei.com/in-focus/3800-trust-the-absent-keystone-in-lebanese-democracy.

Antoun, R. et al. (1998). Waqi' al- Baladiyat fi Lubnan wa 'Awaiq al -Musharika al - Muhaliya wa at-Tanmiya al- Mutawazina. Beirut: Lebanese Centre for Policy Studies.

Atallah, S. (2012). Establishing Regional Administrations for Integrated Development. The Lebanese Center for Policy Studies (LCPS), 2. Retrieved from http://www.lcps-lebanon.org/publications/1347371684-policybrief_2.pdf.

Axelrod, R. (1984). The evolution of cooperation. New York: Basic Books.

Barnard, C. I. (1938). The functions of the executive. Cambridge, MA: Harvard University Press.

Barnett, A., Yandle, B., \& Naufal, G. (2013). Regulation, Trust, and Cronyism in Middle Eastern Societies: The Simple Economics of 'Wasta'. The Journal of Socio-Economics, 44: 41-46.

Barriball, K. L., \& While, A. (1994). Collecting data using a semi-structured interview: a discussion paper. Journal of Advanced NursingInstitutional Subscription, 19(2), 328-335.

Bazzi, M. (2007). Lebanon's Bloody Summer. The Nation. Retrieved from http://www.thenation.com/article/lebanons-bloody-summer.

Bazzi, M. (2009). In Lebanon: New Government, Old Politics. Council on Foreign Relations. Retrieved from http://www.cfr.org/publication/20749/in_lebanon.html.

Beratan K. (2007). A cognition-based view of decision processes in complex social- ecological system. Ecology and Society, 12 (1):27.

Campion, M., Pursell, E., \& Brown, B. (1988). Structured interviewing: Raising the psychometric properties of the employment interview. Personnel Psychology, 41, 25-42.

Cunningham, R.B. \& Sarayrah,Y. (1993). Wasta: The Hidden Force in Middle Eastern Society. Westport, Conn: Praeger.

Denzin, N K. (1989). The Research Act: A Theoretical Introduction to Sociological Methods. $3^{\text {rd }}$ edition Prentice Hall, Englewood Cliffs, New Jersey.

Deutsch, M. (1958). Trust and suspicion. Journal of Conflict Resolution 2, 265-279.

Deutsch, M. (1960). The effect of motivational orientation upon trust and suspicion. Human Relations, 13, 123-139.

Edelenbos, J, and Erik-Hans K. (2007). Trust in complex decision-making networks: A theoretical and empirical explanation. Administration \& Society, 39, 25-50.

Ferrin, D. L., Bligh, M. C., \& Kohles, J. C. (2007).Can I trust you to trust me? A theory of trust, monitoring, and cooperation in interpersonal and intergroup relationships. Group and Organization Management, 32(4), 465-499.

Ferrin, D. L., Bligh, M. C., \& Kohles, J. C. (2008). It Takes Two to Tango: An Interdependence Analysis of the Spiraling of Perceived Trustworthiness and Cooperation in Interpersonal and Intergroup Relationships. Organizational Behavior and Human Decision Processes, 107(2), 161-178.

Fulmer, C. A., \& Gelfand, M. J. (2012). At what level (and in whom) we trust: Trust across multiple organizational levels. Journal of Management, 38, 1167-1230.

Gilson, L. (2003). Trust and the development of health care as a social institution. Social Science and Medicine 56, $1453-1468$.

Gray, S., R. Shwom, and R. Jordan. (2012). Understanding factors that influence stakeholder trust of natural resource science and institutions. Environmental Management 49(3):663-674.

Habib, A. (2012). Demography and Socio-Economic Characteristics of the Lebanese Coastal Population. In Review and perspectives of environmental studies in Lebanon (pp. 265-295). Edited by Kouyumjian \& Hamze, National Council for Scientific Research. Lebanon. 
Haddad, S. (2002). The relevance of political trust in postwar Lebanon. Citizenship Studies 6 (2):201-218.

IMAC. (2007a). Status Report. Integrated Management of East Mediterranean Coastlines: North Lebanon project. Institute of the Environment, University of Balamand.

IMAC. (2007b). Assessment of the institutional and legal setting for coastal zone management in Lebanon: Final report. Integrated Management of East Mediterranean Coastlines: North Lebanon project. Institute of the Environment, University of Balamand.

IMAC. (2009). IMAC Project Summaries. Integrated Management of East Mediterranean Coastlines: Northern Lebanon project. Institute of the Environment, University of Balamand.

Ker Rault, PA. (2009). Reconsidering public participation and governance style in integrated water management: moving towards pragmatic contextual participative strategy. In Jenny Pope (Ed.), IAIA Ghana Conference Proceeding (pp. 1-6). Fargo, USA: IAIA. Retrieved from http://www.iaia.org/iaia09ghana/documents/cs/CS2-5_Reconsidering-public-participation-and-governance.pdf.

Koeszegi, S. T. (2004). Trust-building strategies in inter-organizational negotiations. Journal of Managerial Psychology, 19, 640-660.

LCPS. (1996).Policy Paper on the Environment in Lebanon. The Lebanese Center for Policy Studies. Retrieved from http://www.Icpslebanon.org/publication.php?id=94\&show=summary.

Leenders, R. 2012. Spoils of Truce: Corruption and State-building in Postwar Lebanon. Ithaca: Cornell University Press.

Lundin, M. (2007). Explaining cooperation: How resource interdependence, goal congruence, and trust affect joint actions in Policy Implementation. Journal of Public Administration Research and Theory, 17(4), 651-672.

Ministry of Environment /UNDP/ECODIT. (2011). State and trends of the Lebanese environment, 2010. Retrieved fromhttp://test.moe.gov.lb/Documents/Cover\%20and\%20Front\%20Matter.pdf.

Möllering, G. (2006). Trust: Reason, routine, reflexivity. Oxford: Elsevier.

Mwangi, SW. (2000). Partnerships in urban environmental management: an approach to solving environmental problems in Nakuru, Kenya. Environment and Urbanization, 12 (2), 77-92.

Ostrom E. and Walker J. (2003). Trust and reciprocity: interdisciplinary lessons for experimental research. In: Ostrom E, Walker J (eds) The Russell sage foundation series on trust. Russell Sage Foundation, New York, p 409.

Ostrom E. (2007). Collective action and local development processes. Sociologica 3:1-32.

Pahl-Wostl, C. (2007). The implications of complexity for integrated resources management. Environmental Modelling \& Software, 22(5), 561-569. Retrieved from http://ac.els-cdn.com.

Parkhe, A. (1993). Strategic alliance structuring: A game theoretic and transaction cost examination of interfirm cooperation. Academy of Management Journal, 36, 794-829.

Pilisuk, M., \& Skolnick, P. (1968). Inducing trust: A test of the Osgood proposal. Journal of Personality and Social Psychology, 8, 121133.

Sackett, P. R. (1987). Assessment centers and content validity: Some neglected issues. Personnel Psychology, 40: 13-25.

Sarraf, M. et al. (2004). Cost of Environmental Degradation: The case of Lebanon and Tunisia. Paper No. 97. Environment Department, World Bank. Washington, DC. Retrieved from http://www.moe.gov.lb/Documents/CostEnvDegLebanonTunisiaJune04EDP98.pdf.

Smith, P. B., H. J. Huang, C. Harb, and C. Torres. (2012). How Distinctive Are Indigenous Ways of Achieving Influence? A Comparative Study of Guanxi, Wasta, Jeitinho, and "Pulling Strings". Journal of Cross-Cultural Psychology, 43(1): 135-150.

Takshe, A.A., et al. (2010). Dealing with pollution from conflict: Analysis of discourses around the 2006 Lebanon oil spill. Journal of Environmental Management, 91(4), 887-896.

Tennberg, M. (2007). Trust in international environmental cooperation in Northwest Russia. Cooperation and Conflict, 42(3), 321-335.

Tsang, S., Burnett, M., Hills, P., \& Welford, R. (2009). Trust, public participation and environmental governance in Hong Kong. Environmental Policy and Governance, 19, 99-114.

Tyler, T. R. (2003). Trust and democratic governance. In V. Braithwaite \& M. Levi (Eds.), Trust and governance (pp. 269-294). New York: Sage.

Wakim, N. (1998). Al-Ayadi as-Sawd. Beirut: Shirkat al Matbu'at li-al-Tawzi' wa al-Nashr.

Woolthuis, R. K. (1999). Sleeping with the enemy: Trust, dependence and contracts in inter organizational relationships. Enschede, Netherlands: Universiteit Twente.

World Bank. (2007). "Republic of Lebanon Economic Assessment of Environmental Degradation Due to July 2006 Hostilities." Report No. 39787-LB, Sustainable Development Department Middle East and North Africa Region. 